\title{
An easy test but a hard decision: ethical issues concerning non-invasive prenatal testing for autosomal recessive disorders
}

\author{
Heather Skirton ${ }^{\star, 1}$, Lesley Goldsmith ${ }^{1}$ and Lyn S Chitty ${ }^{2}$
}

Prenatal testing based on cell-free fetal DNA in maternal serum is now possible for specific monogenic conditions, and studies have shown that the use of non-invasive testing is supported by prospective parents and health professionals. However, some ethical issues have been raised concerning informed consent and paternal rights. The objective of this study was to explore ethical aspects of the use of non-invasive prenatal diagnostic testing for autosomal recessive disorders. We used a qualitative cross-sectional design, based on Thematic Analysis, and recruited 27 individuals of reproductive age who were carriers of one of four conditions: thalassaemia, sickle cell disease, cystic fibrosis or spinal muscular atrophy. Data were collected via focus groups or interviews. Participants were aware of the potential for such tests to be viewed as routine and suggested that obtaining written consent and allowing time for consideration is needed to facilitate autonomous choice and informed consent. All participants felt that mothers should be able to request such tests, but fathers who declined carrier testing should be made aware that fetal test results may reveal their status. We suggest that a written record of consent for non-invasive prenatal diagnosis should be used as a standard to help reinforce the serious nature of the test results. Where the father's carrier status could be revealed through fetal testing, he should be made aware of this before the results are available. Health professionals should discuss with the pregnant woman the best way to manage unsought information about the father's carrier status to minimise family disruption. European Journal of Human Genetics (2015) 23, 1004-1009; doi:10.1038/ejhg.2014.238; published online 5 November 2014

\section{INTRODUCTION}

For over five decades, invasive prenatal testing has been available for pregnant women whose fetus is at high risk of having either a chromosome anomaly such as Down syndrome ${ }^{1}$ or a single gene disorder such as cystic fibrosis. ${ }^{2}$ Cells for analysis are obtained using either chorionic villus sampling (CVS) at 10-13 weeks' gestation or amniocentesis (usually undertaken around 16 weeks gestation). ${ }^{3}$ Each of these invasive procedures carries a risk of approximately $0.5-1 \%$ of miscarriage. ${ }^{4}$

As the discovery of cell-free fetal DNA in maternal blood is over 15 years ago, ${ }^{5}$ the analysis of cell-free fetal DNA has been implemented for specific clinical applications such as fetal sex-determination to support the prenatal diagnosis of $\mathrm{X}$-linked disorders ${ }^{6}$ and fetal $\mathrm{RhD}$ status. ${ }^{7}$ Research on the use of non-invasive prenatal diagnosis (NIPD) for the diagnosis of single gene disorders has to implementation for some conditions ${ }^{8}$ and there is considerable support by prospective parents and health professionals for further development in this area. ${ }^{9,10}$

European guidelines on the provision of prenatal-testing stress the need for prenatal testing to be offered without coercion, and also that provision of accurate, understandable information be provided to ensure a fully informed choice. ${ }^{11}$ These principles apply to both invasive and non-invasive tests; however, there is some evidence to show that prenatal testing may be considered by parents as routine rather than optional. ${ }^{12,13}$ There are also concerns that prenatal diagnosis itself can be viewed as 'eugenic' and discriminatory against people with disability. ${ }^{14,15}$ While service users cite the earlier timing of the test and safety for the fetus ${ }^{16}$ as major advantages of NIPD, health professionals were positive, but expressed reservations such as concerns about informed consent and potential 'routinisation' of a test that can be done on a 'simple' blood test. ${ }^{17}$ It is clear, therefore, that before the full implementation of NIPD into clinical practice, ethical and social issues should be explored. ${ }^{18}$

Specific ethical issues around NIPD were outlined in a paper by Deans et $a l,{ }^{19}$ who used examples to illustrate how the ethical principles of autonomy, privacy and fairness could be at risk with the use of NIPD. Potential ethical concerns included the potential for routinisation and the undermining of informed consent. Those authors also raise the possibility that because NIPD is based on a maternal blood test and is somewhat safer and easier to use than invasive testing, a mother may therefore opt to have NIPD for an autosomal recessive condition for which she is a carrier, even if the father does not wish to know his carrier status. In autosomal recessive conditions such as sickle cell anaemia where there is only one disease causing mutation, the fetus can only be affected if both parents are carriers. ${ }^{20}$ If the fetus is tested and found to be affected, this result would indicate that the father is a carrier, despite his preference not to know. This could also occur with invasive testing, but the absence of risk to the fetus may make the mother's decision to test more likely. This scenario cannot currently be applied to many other autosomal recessive conditions as it is not yet possible to test for all possible causative mutations using NIPD. However, it has the potential to

${ }^{1}$ Faculty of Health and Human Sciences, Plymouth University, Plymouth, UK; ${ }^{2}$ UCL Institute of Child Health, Great Ormond Street and UCLH NHS Foundation Trusts, London, UK *Correspondence: Professor H Skirton, Faculty of Health and Human Sciences, Plymouth University, 3 Portland Villas, Drake Circus, Plymouth PL4 8AA, UK, Tel: +44 1752 586569; E-mail: heather.skirton@plymouth.ac.uk

Received 9 July 2014; revised 17 September 2014; accepted 19 September 2014; published online 5 November 2014 
apply a wider range of recessive conditions with increasing use of next generation gene panels which can be used in NIPD to detect multiple disease causing mutations.

The aim of this study was to explore the ethical issues involved in the use of NIPD for single gene disorders in depth. In particular, we wished to explore the views of carriers of recessive conditions about this type of test; to examine issues around informed consent for testing single gene disorders, and finally, to investigate the views of potential users of NIPD regarding fathers' rights.

\section{MATERIALS AND METHODS}

We based this study on Thematic Analysis, ${ }^{21}$ a qualitative approach suitable for exploratory studies.

\section{Recruitment and participants}

We aimed to recruit carriers of four autosomal recessive conditions: cystic fibrosis, thalassaemia, spinal muscular atrophy and sickle cell disease. These conditions were chosen because of the different types of impact of the condition on the life of the affected person. We wished to obtain a maximum variation sample of participants of both genders and from a range of ethnic groups, ages and reproductive experience. Initially we recruited participants by advertising through the relevant patient support groups or organisations. This was successful in the case of carriers of cystic fibrosis, thalassaemia and spinal muscular atrophy. We also tried to recruit carriers of sickle cell disease through health services and clinics for the condition, as well as via website advertisements and Twitter.

\section{Data collection}

We originally planned to collect data using focus groups, as this method enables the views of multiple participants to be heard and allows for dynamic conversation between participants. ${ }^{22}$ We used a semi-structured approach and a range of open questions to explore the topics of interest. However, it became apparent that, due to the rarity of the conditions and the geographical spread of potential participants, this was not feasible. We therefore offered telephone interviews (using the same semi-structured question schedule) for those for whom focus group attendance at a focus group was not practical. We aimed to recruit at least six carriers of each condition and managed this except in the case of sickle cell disease, where despite many attempts to recruit through different methods we managed to recruit only one carrier.

With regard to the semi-structured questionnaire, we asked participants about their experience of the condition in the family, their knowledge of prenatal diagnosis and opinions of the use of NIPT. All participants were carriers and in the majority of cases so were their partners: the issue of NIPT was therefore a practical consideration for them in any future pregnancies. We felt it was important to determine how people viewed NIPT outside of the highly emotive situation during a pregnancy, and because the participants were not pregnant, this enabled us to ask more sensitive questions than we would have asked during a current pregnancy. In addition, we asked for their opinions about a hypothetical ethical situation where a father did not wish to have carrier testing, as discussed by Deans et al. ${ }^{19}$

\section{Data analysis}

Data were transcribed verbatim, anonymised and analysed thematically. ${ }^{21}$ The process of data collection and analysis ran concurrently. Each statement was coded and grouped into categories and finally themes. Coding was conducted independently by two researchers (HS and LG) and consensus was then reached on the major categories and themes.

\section{Ethical issues}

This work formed a part of the RAPID programme (NIHR PGfAR RPPG-0707-10107), for which National Health Service Research Ethics Committee approval was obtained in June 2010. All participants were provided with information about the study prior to agreeing to take part and were aware that they could withdraw at any time. A written record of their consent was obtained. The confidentiality of each participant has been protected by using pseudonyms and removing or altering details that could enable them to be identified in this report.

\section{Ensuring rigour}

The first two authors are experienced qualitative researchers. The first author is a qualified midwife and registered genetic counsellor, the third is an expert in genetics and fetal medicine, and all three authors have personal experiences of pregnancy. They therefore brought a set of values and beliefs on this topic, based on professional and personal experience, to the research. For the purposes of the research, it was necessary to be aware of these prior conceptions and ensure that the data collection and analytical procedures were robust to reduce chances of subjectivity influencing the findings. This was done by ensuring the interviews were conducted by a experienced qualitative researcher and by having two researchers independently coding the data. In addition, we provided a number of the participants with a report on the findings and asked for their feedback as to whether they represented their views in a balanced way.

\section{Findings}

Table 1 provides an overview of the demographic characteristics of the participants. We have not included all characteristics in the individual table (Table 2) to protect the participants from being identified. As can be seen in Table 2, 8 of the 27 participants were male. There were 11 participants who were carriers of cystic fibrosis, seven who were carriers of thalassaemia (including one affected person), one who was a carrier of sickle cell disease and eight who were carriers of spinal muscular atrophy (including one affected person). Twenty-one of the participants had a partner who was also a carrier. The ages of participants ranged from 16 to 54 years. The findings are presented under the following main themes: perceptions of the test, preparation for decision making and paternal rights.

\section{Theme: perceptions of the test}

There was overwhelming support for the introduction of NIPD for single gene disorders. The safety aspect of the non-invasive test was paramount for many respondents:

Table 1 Summary of demographic characteristics

Condition

\begin{tabular}{|c|c|c|c|c|}
\hline Characteristic & Thalassaemia & Cystic fibrosis & Spinal muscular atrophy & Sickle cell disease \\
\hline Number & 7 & 11 & 8 & 1 \\
\hline Ethnicity & $\begin{array}{l}\text { White other }=3 \\
\text { British Asian }=4\end{array}$ & $\begin{array}{l}\text { White } \text { British = 10, } \\
\quad \text { Persian = } 1\end{array}$ & $\begin{array}{c}\text { White British }=7 \\
\text { White British/White other }=1\end{array}$ & $\begin{array}{c}\text { African American/White } \\
\text { British }=1\end{array}$ \\
\hline Number with children & 4 & 9 & 7 & 0 \\
\hline Number with affected children & 2 & 6 & 7 & 0 \\
\hline Previous prenatal diagnosis (self or partner) & 2 & 1 & 4 & 0 \\
\hline Pre-implantation genetic diagnosis & 0 & 2 & 2 (both unsuccessful) & 0 \\
\hline
\end{tabular}


Table 2 Individual characteristics

\begin{tabular}{|c|c|c|c|c|c|c|}
\hline Pseudonym & Gender & Age range & Marital status & Condition & Number of children/ pregnancy losses & Prenatal tests in the past \\
\hline Anna & Female & $20-29$ & Single & Thalassaemia & 0 & No \\
\hline Stelios & Male & $50-59$ & Married & Thalassaemia & 1 & No \\
\hline Elia & Female & $16-19$ & Single & Thalassaemia & 0 & No \\
\hline Nelly & Female & $40-49$ & Married & Thalassaemia & 2 Children, 1 miscarriage & CVS $\times 2$ \\
\hline Shehla & Female & 30-39 & Married & Thalassaemia & Pregnant with first child & No \\
\hline Rita & Female & 30-39 & Married & Thalassaemia & 2 Children, 1 affected and 1 unaffected & CVS $\times 1$ \\
\hline Mushtaq & Male & 30-39 & Married & Thalassaemia & As above & Wife had CVS \\
\hline Lydia & Female & 20-29 & Single & Sickle cell disease & 0 & No \\
\hline Deidre & Female & 30-39 & Living with partner & Cystic fibrosis & 3 Children, 1 affected & No \\
\hline Ayse & Female & 20-29 & Married & Cystic fibrosis & 1 Child, affected & No \\
\hline Ray & Male & 30-39 & Married & Cystic fibrosis & 0 & Currently having PGD \\
\hline Melissa & Female & 30-39 & Married & Cystic fibrosis & 0 & Currently having PGD \\
\hline Philip & Male & 30-39 & Married & Cystic fibrosis & 1 Child, affected & Considering PGD \\
\hline Chris & Male & 30-39 & Married & Cystic fibrosis & 2 Children, wife pregnant & No \\
\hline Faye & Female & $20-29$ & Married & Cystic fibrosis & 1 Child, affected & No \\
\hline Rose & Female & $30-39$ & Married & Cystic fibrosis & 1 Child, affected & No \\
\hline Matt & Male & $30-39$ & Married & Cystic fibrosis & 1 Child, affected & No \\
\hline Jakki & Female & $40-49$ & Married & Cystic fibrosis & 2 Children, 1 affected & Yes. CVS x1 \\
\hline Marie & Female & 30-39 & Married & Cystic fibrosis & 1 Child, affected & No \\
\hline Karen & Female & $20-29$ & Living with partner & SMA & 0 & No \\
\hline Jenny & Female & $30-39$ & Married & SMA & 3 Children, 1 who died of SMA & Yes \\
\hline Rob & Male & 30-39 & Married & SMA & 3 Children, 1 who died of SMA & Wife had PND \\
\hline James & Male & $40-49$ & Married & SMA & 3 Children, 1 died of SMA & Wife had PND \\
\hline Tessa & Female & $40-49$ & Married & SMA & 3 Children, 1 died of SMA & CVS $\times 2$ \\
\hline Rachel & Female & 40-49 & Married & SMA & 2 Children, 1 died of SMA. 2 miscarriages & No. PGD unsuccessful \\
\hline Alexis & Female & 30-39 & Married & SMARD & 4 Children, 1 died of SMARD & No \\
\hline Amelie & Female & $40-49$ & Married & SMA & 1 Child, died of SMA & No. PGD unsuccessful \\
\hline
\end{tabular}

'there isn't really any downside .... [either] have a test that has $1 \%$ chance of you having a miscarriage or no percent chance - it's a no brainer'. (Rachel, SMA carrier)

'I think it would take a lot of the worry away. ....the reason that we were put off with the first one to do the test was the risk of miscarriage ...' (Rita)

For some, the earlier access to results was a benefit:

'I think the earlier you know, you sort of get yourself into that mind frame of what can you expect... having to wait that long to know whether your child has got CF or not is awful really.... I know it's a little bit earlier, but it's still earlier.' (Ayse)

Heavy emphasis was put on the accuracy of the test....

'I would want it to be as high as it possibly could be. ... as close to $100 \%$ as it possibly could be.' (Amelie)

However some of the advantages were framed in such a way as to indicate that routinisation of the test was a possibility.

'if you do go down the amnio route... you are making a very deliberate choice, so you probably consider all the options before you get to the point of having the test done, whereas the blood test...like all the other blood tests that get done for whatever, but whether you are prepared enough for that, because it is almost routine. I mean, you have blood taken for all sorts of things and it becomes a routine thing, are you fully aware of the potential consequences of that result? (Chris)

'at the end of the day it is a blood test and obviously through your pregnancy you have blood tests anyway ...so to me it would just be another blood test like that ....there is actually no disadvantages to having a blood test... so I think the chances are they are more likely to get more people going for that test' (Nelly)

However, it was felt that this tendency for the test to be viewed as routine could be counteracted somewhat by greater attention to consent and giving time for consideration, as discussed below.

When asked about disadvantages, several people spoke of the moral issues related to prenatal testing, rather than disadvantages of NIPD per se. They all concluded that prenatal testing was a matter of individual choice.
'Not really disadvantages, only disadvantages in the sense of like pro life, if people are going to think about not having babies because they could have sickle cell disease, is that the kind of, is that positive way of the world or can people live with sickle cell... I think it is down to the individual and everyone has to make the decision for themselves.' (Lydia).

\section{Theme: preparation for decision making}

We asked the participants what information they felt would be required before a decision could be made to accept or decline an NIPD. It was felt that levels of information may vary, according to the individual parents involved.

'different parents will want to know different levels. I like a lot of information so I would want to know what the test is, how it works, how long the results will take to come, what are the risks of the test, again the accuracy of the test, more about the condition' (Shehla)

However, accuracy of the test, certainty of the result, risks involved and whether there were other options were factors most frequently mentioned.

'what are all the options and then I would look at the accuracy levels of all the options and then the risks associated with each of the options' (Rita)

In particular, many participants expressed the view that if the test results were less certain that those for invasive testing, then they would prefer to have an invasive test.

'Is it a certainty from the result or is it a risk?

RES: So for you, one of the things ....about NIPD would be if it was just given to you as a risk rather than definite diagnosis.

Yes, because I wouldn't see the benefit over CVS.' (Philip)

\section{Theme: informed consent}

We asked participants about the use of a written record of consent (signed consent form) and the time needed to consider the test. Participants recognised that a written consent form was used for invasive testing, while they were not usually asked to record their consent for a blood test. In relation to use of a written consent form for NIPD, the majority felt that this was useful, but cited a 
range of reasons. The most common reason given was to help parents to recognise the serious nature of the test.

'it's so easy to say yes I will do that because everyone else is doing it but not necessarily. I think that reading it, writing it, signing for it just makes it very much more real' (Shehla)

'Yes, potentially it is very serious. It's not just having a small test to find out something like whether you are pregnant or not it's actually going into more detail-I do think it's very serious, yes I do think that having a form that you have to sign would make people think about it more' (Karen)

However, a number of participants, voiced the opinion that the consent form was

meant to protect health professionals:

it might be an idea to have a consent form saying this is what we are looking for and this is what you have agreed to. So if you ... discover something and this is what I don't want to know. So the consent will be to cover the health professionals really. (Nelly)

Others stressed that the genetic nature of the test meant that consent should be recorded.

RES: So it's that thing about genetic material being a serious test?

Faye: And the storage thing

Rose: [And whether it could be abused] or not.

Faye: You need to be able to sign to say whether you're happy for your genetic material to be stored, because that also is the genetic material of your baby isn't it? Yes, I think any kind of testing on your genetic material, because of its implications for lots of other people, you know, family and everything, I think it is a really serious piece of information.'

\section{Theme: paternal rights}

Participants in our study generally viewed the decision to have an NIPD as one that should be made by both parents.

'I think that it is something that together that family should have to come to an agreement together.' (Karen)

However, one mother disagreed as her husband had not taken any part in previous decisions to have invasive testing and she felt it was only the business of the mother:

'My husband has never had a conversation about it ever. Doesn't want to know, doesn't think it will affect his life, doesn't want to talk about it.

RES: So how did that work when you had your test in the pregnancy?

He didn't have anything to do with it. I don't think there is an obligation even in CVS to inform the father of anything....... I think you have to rule out the fact that it is anything to do with anybody else but the mother' (Rachel)

Although the same situation may arise with invasive testing, participants felt it may be more likely because of the greater ease of testing.

'Definitely, obviously she is more likely to want that blood test and sort of you can give that test to a lot more patients than the invasive test.... a test like a blood test is so much more widespread. It can be offered to many more people especially like you say if the father is unknown or not around or declines to be tested.' (Nelly)

'hopefully that would be discussed with you before you got pregnant. So, you and partner could take that into account before you even start the whole process' (Marie)

Participants were unanimous in thinking that if the parents disagreed about having NIPT, then the mother ultimately had the right to make the decision.

'I think my personal view is maybe because I am the mother is that the mother should have the right to have the test done. Ideally with the partner's consent but if the partner is not consenting, this is a difficult one, but I would suggest that the choice should be the mother's.' (Shehla)

'I don't think there is an ethical issue here. At the end of the day if there is a father who doesn't want to know and the mother says I have done it and this is the result it's the mother's choice.' (Stelios)

'from our point of view is that we would have a discussion about something but ultimately I like would have said it was Jenny's decision. If we had had a disagreement I would have felt that we would have gone with what she wanted because it is happening to her not me.' (Rob)

We posed the ethical question of the rights of the father not to know his own carrier status by presenting a scenario where the carrier mother wished to have the fetus tested, but the father did not wish to know if he was a carrier. In this situation, if the fetus was found to be affected the father's status as a carrier would be revealed.

The concept of a father not wishing to have a carrier test that would provide information about the risk of a condition to the fetus was incomprehensible to the men who took part in our study.

'I couldn't understand why a father wouldn't want to know. I mean I would want to know if I was a carrier or not personally ....very strange people. Well yes I know we all have rights and one thing and another, there is too much of that going on, but if the mother wants to know then I am sure she should have some rights in it as well to find out' (James)

Some participants felt that the situation was unlikely in communities where the male traditionally took a very active role in caring for and raising the family, but may be more likely in situations where the father was 'absent'.

'Now it also doesn't really affect thalassaemia so much with regard to the parent, the fathers, the fathers are usually $95 \%$ of them there' (Stelios)

The attitude of most participants was that the father should face his responsibilities, and that the interests of the mother and the fetus far outweighed his own wish not to know.

Jakki: if a guy says 'I'd really rather not know', I could - well 'Man up and deal with it!' Sorry....

Rose: That's the risk you take by creating a baby together though, isn't it?'

'I would question why he doesn't want the test really. It's.just a blood test for him isn't it, it's nothing major. He is not particularly being fair to his partner I don't think by refusing the test.' (Tessa)

However, many also felt that this was a sensitive situation and that the father should be made aware before the NIPD was performed that the outcome could result in information about his carrier status.

'Does the man understand the implications, does he realise that if he doesn't find out then and it turns out that he is then their child could be born with a terminal illness. I think that is a hard thing to generalise because people have different opinions and views on things. I think the only thing you can do in those circumstances is have some kind of information, fact sheet, that you know can be given to them as a couple...... if it comes back positive then you are diagnosing somebody with them having already decided that they didn't wasn't to be tested for something. I never realised these things were so complicated.' (Amelie)

Where the father's status was revealed without his consent, the participants were divided. Some felt that a health professional should convey the results, although they acknowledged that if the father was still involved in the life of the child it was inevitable that he would become aware of his own carrier status.

'Health professionals, obviously you can't guarantee what the situation is going to be like between the parents so you know you are opening a whole can of worms by doing that so I think it is going to be health professionals. It is a funny one, it's a case of if the father is a carrier then .... he is going to find out he is a carrier one way or the other' (Nelly)

Others felt that if the mother took the decision to have the test, then she should communicate the results to the father.

'I just wonder why they wouldn't want to find out that, and the reasons behind that would probably sort of dictate how you deal with it. So, for instance, I don't know, from a religious point of view or something like that, then you would deal with it, maybe tailor it accordingly. Because of that, if you ask the person to give some indication of why they wouldn't want to find out, whether they discuss it with their partner first when they are offered the test, so that's it's up to, the onus isn't on the professional doing the test to give that advice, or to say who should find out or not - but it's within the realms of the family so you have to tell the person who is being tested, and whether that information is passed on or not is, like, up to that family group.

RES: So the professionals shouldn't really interfere with the family dynamic, the family communication.

P: I don't think so, because, I mean, like you said, the father is going to find out at some point anyway, ...., but um I think that if the mother has chosen to have that test, then the onus is on the mother to tell the father.' (Philip)

However, one person felt that the father should not be informed of his status if he had made a decision that he did not wish to know.

'I think people have the right to say for themselves if they don't want to know then you have tried 
RES: So you think that we shouldn't be telling him if he has said he doesn't want to know

I guess not, if it's not something he doesn't want to know.' (Lydia)

\section{DISCUSSION}

The findings regarding the characteristics of the test and perceived advantages were very consistent with those of other studies on this topic. ${ }^{10,23,24}$ With regard to the ethical aspects of offering NIPD for single gene disorders, our participants expressed their view that there was a significant possibility that the test would be accepted by prospective parents with less prior thought and decision-making than when invasive testing was offered. They stressed that it was not the test, but the implications of the results for the pregnancy, that made informed consent vital. These findings reinforce those of Hill et al ${ }^{23}$ and could make it more challenging for health professionals to obtain informed consent.

Deans et al ${ }^{19}$ raise the issue of a potential moral conflict between the pregnant woman and her partner regarding fetal testing. With regard to this type of conflict, all of the participants in the current study felt that the mother had the ultimate right to request fetal testing, but that fathers had a moral duty to put the best interest of the mother and fetus before their own concerns by having carrier testing, even when they did not wish to know their own status. Authors of a study undertaken in South Africa ${ }^{25}$ suggested that enabling women to make reproductive decisions (such as termination of pregnancy) may interfere with the father's wish to protect the child. Our findings seem to contradict that suggestion, as the participants felt strongly to the contrary, that fathers had a duty to protect their offspring through involvement in the testing process. These disparate findings may be due to the focus of our study, where all participants were at risk of having a child with a recessive condition, compared with the males not known to have specific genetic risks in the South African study. It is of interest that one male carrier in our study suggested that reluctance of fathers to have carrier testing was unlikely to be an issue in families affected by thalassaemia. However, Yang et $a l^{26}$ reported that in a group of nine children born in a Chinese hospital who were severely affected by $\beta$-thalassaemia, in four cases this occurred because the father was unavailable for carrier testing. Cultural differences must be taken into account and it is important not to presume that parents from one or other condition group will act similarly. Another factor that may predispose to paternal absence is maternal adolescence, as genetic counsellors reported that young mothers were much less likely to be accompanied to prenatal genetic counselling clinics by the baby's father than older mothers. ${ }^{27}$

In a study on carrier testing during the pregnancy, Ormond et al ${ }^{28}$ suggested that the person being offered a test required information about: the condition, implications of being a carrier, potential further options if carrier testing was positive and resources available for caring for an affected child. If after giving this information the parent declines testing, he or she may be making an informed decision. However, in a situation where the father is not 'present' and declines to engage with the health professionals involved, the father is exercising a right not to be informed. This is his right, but there is a further dilemma in this instance if the mother has a prenatal test that indicates the fetus is affected. The mother and health professional are then left with the information about the father's carrier status that by rights belongs to him. When this issue was raised, participants were concerned to find the best way to handle the information with minimal disruption to the family dynamics. Some felt this would be best achieved if the health professional took responsibility for disclosure (thus taking the responsibility for delivering the news from the mother), while others felt it was better if health professionals were not involved except if support were needed. These divergent views indicate that discussion with the mother as to the best way of optimising positive family relationships should take place.

\section{Strengths and limitations of the study}

In this study, we succeeded in recruiting a maximum variation sample of adults of childbearing age with regard to age, gender and reproductive experience. We recruited a range of carriers of three conditions, but despite strenuous efforts failed to recruit sufficient carriers of SCD and their views or the views of carriers of other recessive conditions may therefore not be represented. We took care to ensure that data analysis was undertaken independently by two researchers, to enhance trustworthiness of the findings. While it could be considered that telephone interviews limit emotional expression, we found that participants were willing and able to disclose their emotional reactions to their circumstances and indeed, it was essential that the interviewer was a skilled and experienced counsellor to minimise the potential to cause distress for the participants.

\section{CONCLUSIONS}

In conclusion, there are implications for practice arising from this work. We would suggest that those who offer NIPD should be aware of the risk of routinisation and ensure that parents have time and the appropriate information to make an informed decision. We also recommend that a written record of consent for NIPD is used as standard to help reinforce the serious nature of the test results. Where the father's carrier status could be revealed through fetal testing, he should be made aware of this before the results are available and health professionals should discuss with the pregnant woman the best way to manage unsought information about the father's carrier status to minimise family disruption.

NIPD has potential to bring numerous advantages to couples who are at risk of having a child with an autosomal recessive condition, however, it is important that health professionals are aware of the potential ethical issues that may arise and prepare to address them pro-actively.

\section{CONFLICT OF INTEREST}

The authors declare no conflict of interest.

\section{ACKNOWLEDGEMENTS}

We acknowledege the support of Leigh Jackson and Anita O'Connor in proofreading the manuscript and suggesting improvements. This manuscript presents independent research funded by the National Institute for Health Research (NIHR) under the Programme Grants for Applied Research Programme (RP-PG-0707-10107; the 'RAPID' project). LSC is partially funded by the Great Ormond Street Hospital Children's Charity and the NIHR Biomedical Research Centre at Great Ormond Street Hospital. The views expressed are those of the authors and not necessarily those of the NHS, the NIHR or the Department of Health.

\footnotetext{
1 Wolstenholme J, Rooney DE: Cytogenetics in the 1970s and 1980s. Prenat Diagn 2010; 30: 605-607.

2 Raymond FL, Whittaker J, Jenkins L, Lench N, Chitty LS: Molecular prenatal diagnosis: the impact of modern technologies. Prenat Diagn 2010; 30: 674-681.

3 Collins SL, Impey L: Prenatal diagnosis: types and techniques. Early Hum Dev 2012; 88: 3-8.

4 Tabor A, Alfirevic Z: Update on procedure-related risks for prenatal diagnosis techniques. Fetal Diagn Ther 2010; 27: 1-7

5 Lo YMD: Presence of fetal DNA in maternal plasma and serum. Lancet 1997; 350 485-487.
} 
6 Finning KM, Chitty LS: Non-invasive fetal sex determination: impact on clinical practice. Semin Fetal Neonatal Med 2008; 13: 69-75.

7 Clausen FB: Integration of noninvasive prenatal prediction of fetal blood group into clinical prenatal care. Prenat Diagn 2014; 34: 409-415.

8 Lench N BA, Fielding S, McKay F, Hill M, Jenkins L, White H, Chitty L: The clinical implementation of non-invasive prenatal diagnosis for single gene disorders: challenges and progress made. Prenat Diagn 2013; 33: 555-562.

9 Lewis C, Hill M, Skirton H, Chitty LS: Non-invasive prenatal diagnosis for fetal sex determination: benefits and disadvantages from the service users' perspective. Eur J Hum Genet 2012; 20: 1127-1133.

10 Hill M, Compton C, Lewis C, Skirton H, Chitty LS: Determination of foetal sex in pregnancies at risk of haemophilia: a qualitative study exploring the clinical practices and attitudes of health professionals in the United Kingdom. Haemophilia 2012; 18: 575-583.

11 Skirton H, Goldsmith L, Jackson L, Lewis C, Chitty L: Offering prenatal diagnostic tests: European guidelines for clinical practice guidelines. Eur J Hum Genet 2013; 22: 580-586.

12 Potter BK, O'Reilly N, Etchegary $\mathrm{H}$ et al: Exploring informed choice in the context of prenatal testing: findings from a qualitative study. Health Expect 2008; 11: 355-365.

13 Barr O, Skirton $\mathrm{H}$ : Informed decision making regarding antenatal screening for fetal abnormality in the United Kingdom: a qualitative study of parents and professionals. Nurs Health Sci 2013; 15: 318-325.

14 Newson AJ: Ethical aspects arising from non-invasive fetal diagnosis. Semin Fetal Neonatal Med 2008; 13: 103-108.

15 Benn PA, Chapman AR: Ethical challenges in providing noninvasive prenatal diagnosis. Curr Opin Obstet Gynecol 2010; 22: 128-134.

16 Lewis C, Hill M, Skirton H, Chitty LS: Non-invasive prenatal diagnosis for fetal sex determination: benefits and disadvantages from the service users' perspective. Eur J Hum Genet 2012; 20: 1127-1133.
17 Hill M, Karunaratna M, Lewis C, Forya F, Chitty L: Views and preferences for the implementation of non-invasive prenatal diagnosis for single gene disorders from health professionals in the United Kingdom. Am J Med Genet A 2013; 161A: 1612-1618, n/a-n/a.

18 Benn PA, Chapman AR: Ethical challenges in providing noninvasive prenatal diagnosis. Curr Opin Obstet Gynecol 2010; 22: 128-134.

19 Deans Z, Hill M, Chitty LS, Lewis C: Non-invasive prenatal testing for single gene disorders: exploring the ethics. Eur J Hum Genet 2013; 21: 713-718.

20 Skirton H: PC. Genetics for the Health Sciences. SCION publications: Oxford, 2009.

21 Braun V, Clarke V: Using thematic analysis in psychology. Qual Res Psychol 2006; 3 . 77-101.

22 Kevern J, Webb C: Focus groups as a tool for critical social research in nurse education. Nurse Educ Today 2001; 21: 323-333.

23 Hill M, Compton C, Karunaratna M, Lewis C, Chitty L: Client views and attitudes to noninvasive prenatal diagnosis for sickle cell disease, thalassaemia and cystic fibrosis. J Genet Couns 2014; e-pub ahead of print 3 May 2014.

24 Allyse M, Sayres LC, Goodspeed TA, Cho MK: Attitudes towards non-invasive prenatal testing for aneuploidy among US adults of reproductive age. J Perinatol 2014; 34: 429-434.

25 Macleod $\mathrm{Cl}$, Hansjee J: Men and talk about legal abortion in South Africa: equality, support and rights discourses undermining reproductive 'choice'. Cult Health Sex 2013; 15: 997-1010.

26 Yang Y, Li D-Z: Birth of children with severe $\beta$-thalassemia at a tertiary obstetric hospital: what are the reasons behind it? Prenat Diagn 2013; 33: 1023-1026.

27 Griswold C, Ashley S, Dixon S, Scott J: Genetic counselors' experiences with adolescent patients in prenatal genetic counseling. J Genet Couns 2011; 20: 178-191.

28 Ormond KE, Iris M, Banuvar S, Minogue J, Annas GJ, Elias S: What do patients prefer: informed consent models for genetic carrier testing. J Genet Couns 2007; 16: 539-550. 